\title{
Dietary carbohydrates and change in physical performance of elderly Europeans: Survey in Europe on Nutrition and the Elderly, a Concerted Action (SENECA) 1993 and 1999
}

\author{
Iben Kynde ${ }^{1,2, *}$, Kirsten S Bjørnsbo ${ }^{1}$, Inge Tetens ${ }^{3}$ and Berit L Heitmann ${ }^{1}$ \\ 'Research Unit for Dietary Studies, Institute of Preventive Medicine, Copenhagen University Hospital, \\ Copenhagen, Denmark: ${ }^{2}$ Biomedical Institute, University of Copenhagen, DK-2200 Copenhagen N, Denmark: \\ ${ }^{3}$ Department of Nutrition, National Food Institute, Technical University of Denmark, Søborg, Denmark
}

Submitted 5 November 2008: Accepted 21 August 2009: First published online 7 October 2009

\begin{abstract}
Objective: To study dietary glycaemic index (GI) and glycaemic load (GL) in association with physical performance in elderly Europeans.

Design: Cross-sectional and prospective study. Physical performance was measured using the Physical Performance Test (PPT) score on a scale from 0 to 27 , where high scores indicate a better physical performance. Habitual diets were measured using diet history interviews and dietary GI and GL were estimated from table values.

Setting: Eight towns/centres from the Survey in Europe on Nutrition and the Elderly, a Concerted Action (SENECA) in 1993 and 1999.

Subjects: Seven hundred and sixty-five men and women, 75-80 years old, were examined in 1993; of these, 357 (47\%) were followed up in 1999, at age 80-85 years.

Results: At baseline, both dietary GI and GL were significantly inversely associated with PPT scores $(P=0.03$ and $P=0 \cdot 05$, respectively). When adjusted for age, BMI, physical activity, self-perceived health, chronic diseases and town/centre, the strength of the associations was attenuated and became non-significant (GI, $P=0 \cdot 08$; GL, $P=0 \cdot 92$ ). Dietary GI/GL were not associated with PPT scores 6 years later. Conclusions: Among elderly Europeans, a high glycaemic diet was associated with a low physical performance at baseline but not 6 years later. Cross-sectional associations may in part be caused by variations in age, BMI, physical activity, self-perceived health, chronic diseases and geographic location.
\end{abstract}

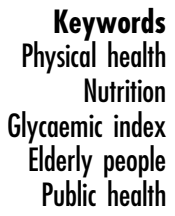

Functional disability is a major predictor of death among elderly people. From age 75 years and onwards, one in ten will lose their independence in performing basic activities with each year of life ${ }^{(1)}$. The quality of the diet plays a role in overall mortality ${ }^{(2)}$, and carbohydrate foods with a low glycaemic index (GI) and glycaemic load (GL) may be of particular importance for elderly people, for whom impaired carbohydrate metabolism and insulin resistance are common conditions ${ }^{(3)}$. A high-GI diet is associated with the risk of acute myocardial infarction among subjects 60 years of age or above but in not those under 60 years old ${ }^{(4)}$. No studies have yet investigated the impact of dietary GI/GL on the physical performance of elderly people.

We hypothesized that a diet with a lower dietary GI/GL is associated with better physical performance. The physiological mechanism of this hypothesis is not completely clear, although it has been suggested that a low dietary GI provides a lower glycaemic response which, in turn, may decrease insulin secretion and longer-lasting glucose availability $^{(5)}$. An improved metabolic homeostasis may improve physical performance ${ }^{(6)}$. Dietary GL is an indirect measure of total insulin demand and represents both the quality (GI) and the quantity of dietary carbohydrates ${ }^{(7)}$.

Based on data from the Survey in Europe on Nutrition and the Elderly, a Concerted Action (SENECA), we investigated the associations between dietary GI/GL and physical performance at baseline and 6 years later.

\section{Methods}

The SENECA is a longitudinal, multi-centre study in men and women, randomly selected from birth cohorts of 1913 to 1918 . The study was initiated in 1988/89 and followed up in 1993 and again in $1999^{(8)}$. Non-eligible 
subjects were those who lived in a psycho-geriatric nursing home, who were not fluent in the country's language, and those who were not able to answer questions independently. In the initial study, the mean response rate of eighteen centres was $51 \%$, varying from $37 \%$ to $62 \%$ between centres ${ }^{(9)}$. Of the about 2600 participants from the initial study, $69 \%$ participated in the study in 1993 and $58 \%$ participated in the study in $1999^{(10)}$. About half of the male population and a quarter of the female population died during the 10-year follow-up ${ }^{(10)}$. A Physical Performance Test (PPT) was introduced in 1993 and repeated in 1999. The present study comprises eight of nine towns/centres participating at both followup studies: Yverdon-les-Bains, Switzerland; Roskilde, Denmark; Betanzos, Spain; Romans, France; Padua, Italy; Culemborg, The Netherlands; Vila France de Xira, Portugal; and Marki, Poland. Sixteen subjects from the Portuguese centre in Coimbra were excluded due to a possible examiner effect, resulting in diverging PPT results between the subjects in Coimbra and the rest of the towns/centres in 1999. Standing height was measured without shoes to the nearest $0 \cdot 1 \mathrm{~cm}$, and body weight was measured in underwear to the nearest $0.5 \mathrm{~kg}$. A total of 765 subjects completed a PPT, a diet assessment, a physical assessment and a general questionnaire in 1993. Of these, 357 subjects completed the PPT in 1999. Between 1993 and 1999, 158 of 765 died, 180 dropped out due to hospitalization, moving away, being on holiday or were unwilling to continue to participate, two had errors in the PPT, and sixty-eight did not state any reason for not participating.

\section{Physical Performance Test}

The PPT is a validated instrument to measure simple overall body functions among older subjects with a relatively high functional status ${ }^{(11)}$. The test, conducted in the homes of the elderly people, consisted of the performance of seven tasks: (i) writing a sentence; (ii) simulating eating with beans on a spoon; (iii) lifting a book and putting it on a shelf; (iv) putting on and removing a jacket; (v) picking up a coin from the floor; (vi) turning $360^{\circ}$; and (vii) walking $15 \mathrm{~m}$. A trained observer counted the seconds used to complete the first six tasks and noted the stability and continuity whereby the seventh task was performed $^{(12)}$. Tasks 1-6 were given scores from 0 to 4 , and task 7 was given a score from 0 to 3 . The total PPT score ranged from 0 to 27 , with a higher score indicating a better physical performance. Reasons for not completing the PPT have been described in detail elsewhere ${ }^{(12)}$.

\section{Dietary assessments}

In 1993, the individual dietary intake was collected using a validated diet history method, consisting of a check-list of foods ${ }^{(13)}$. Food items were related to the meal patterns of the local community with the previous month as the reference period. The diet history method has shown a general acceptable agreement compared with a $3 \mathrm{~d}$ weighted record method among SENECA towns/centres $^{(14)}$. Food data were classified into forty-eight food groups of the EURO-code system ${ }^{(15)}$. Twenty-eight food groups comprised enough carbohydrates to be included in the calculation of dietary GI and GL. Food GI and available carbohydrates (CHO) were obtained from international tables ${ }^{(16)}$ if three principles were met: (i) the studies were implemented on a minimum of six subjects; (ii) the test foods contained $50 \mathrm{~g}$ of available carbohydrates; and (iii) the measuring period was $2 \mathrm{~h}$ for healthy subjects and $3 \mathrm{~h}$ for subjects with diabetes ${ }^{(17)}$. Dietary GI was expressed as a percentage of the overall glycaemic response elicited by white bread: $\Sigma\left(G I_{i} \times C H O_{i} \times W_{i}\right) /$ $\left(\mathrm{CHO}_{i} \times W_{i}\right)$, where $i$ is each of the twenty-eight carbohydrate food groups and $W$ is the total food weight. The dietary GL was estimated by multiplying the dietary GI by a weighted intake of available carbohydrates of each food item ${ }^{(17)}$.

\section{Statistical analysis}

Linear regression models were used to study cross-sectional and prospective associations between dietary GI/ GL quintiles and physical performance at baseline and 6 years later. Analyses were not stratified by sex, as means of PPT scores, dietary GI and GL were similar with equal variations among men and women. Three models were applied:

1. An unadjusted model with the inclusion of baseline PPT scores in the prospective analyses.

2. A semi-adjusted model with additional inclusion of age, BMI, physical activity (grouped as much less, less or averagely active compared with peers $v$. more or much more active compared with peers), self-perceived general health ranging from 1 to 5 (where $1=$ very poor, $2=$ poor, $3=$ fair, $4=$ good and $5=$ very good health) and number of chronic diseases (grouped as no disease/one disease $v$. more than one disease).

3. A fully adjusted model with additional inclusion of town/centre as a random effect.

All statistical analyses were carried out with the SAS statistical software package version 9·1 (SAS Institute Inc., Cary, NC, USA) and graphs were plotted in Sigma Plot 10 (Systat Software Inc., London, UK).

\section{Results}

The cross-sectional analyses included 765 subjects, 353 men and 412 women. Characteristics of the study sample are described in Table 1. Despite $38 \%$ of the participants suffering from more than one chronic disease, $90 \%$ generally considered themselves in fair or (very) good health. Dietary GI, dietary GL and PPT scores varied significantly across towns/centres, all $P<0 \cdot 0001$ (Table 2). 
Table 1 Subject characteristics in the Survey in Europe on Nutrition and the Elderly, a Concerted Action in 1993 ( $n$ 765)

\begin{tabular}{|c|c|c|}
\hline & Mean & SD \\
\hline Sex (\% women) & 54 & - \\
\hline Age (years) & 77 & 2 \\
\hline BMI $\left(\mathrm{kg} / \mathrm{m}^{2}\right)$ & 27 & 4 \\
\hline Self-reported activity (\% not much active*) & 44 & - \\
\hline Self-perceived health (scale 1-5t) & 4 & 1 \\
\hline $\begin{array}{l}\text { Chronic disease (\% with more than } \\
\text { one diseasef) }\end{array}$ & 38 & - \\
\hline PPT score, 1993 (scale 0-27) & 22 & 3 \\
\hline PPT score, 1999 (scale 0-27§) & 20 & 4 \\
\hline Dietary GIII & 85 & 4 \\
\hline Dietary GL\| & 206 & 76 \\
\hline Dietary fibre $(g / d)$ & 20 & 8 \\
\hline Dietary carbohydrate (\% of energy) & 46 & 9 \\
\hline Dietary energy intake (MJ/d) & 8 & 3 \\
\hline
\end{tabular}

PPT, Physical Performance Test; GI, glycaemic index; GL, glycaemic load. *Versus more or much more active compared with peers.

tOrdinal variable from 1 to $5: 1=$ very poor health, $2=$ poor health, $3=$ fair health, $4=$ good health and $5=$ very good health.

IVersus subjects with no disease or one disease. $\S n 357$.

IWhite bread as the reference food with $\mathrm{Gl}=100$.

Table 2 Dietary glycaemic index (Gl), dietary glycaemic load (GL) and Physical Performance Test (PPT) score distributed by eight towns/centres of the Survey in Europe on Nutrition and the Elderly, a Concerted Action in 1993 ( $n$ 765)

\begin{tabular}{|c|c|c|c|c|c|c|c|}
\hline \multirow[b]{2}{*}{ Town/centre } & \multirow[b]{2}{*}{$n$} & \multicolumn{2}{|c|}{$\mathrm{Gl}^{*} \mathrm{t}$} & \multicolumn{2}{|c|}{$G L^{*}+$} & \multicolumn{2}{|c|}{ PPT scoret } \\
\hline & & Mean & SD & Mean & SD & Mean & $\mathrm{SD}$ \\
\hline $\begin{array}{l}\text { Yverdon-les-Bains, } \\
\text { Switzerland }\end{array}$ & 102 & 85 & 3 & 205 & 59 & 23 & 2 \\
\hline Roskilde, Denmark & 94 & 85 & 4 & 233 & 66 & 22 & 2 \\
\hline Betanzos, Spain & 41 & 84 & 7 & 168 & 75 & 21 & 3 \\
\hline Romans, France & 128 & 86 & 3 & 197 & 47 & 24 & 2 \\
\hline Padua, Italy & 110 & 80 & 5 & 129 & 52 & 23 & 3 \\
\hline $\begin{array}{l}\text { Culemborg, } \\
\text { The Netherlands }\end{array}$ & 97 & 85 & 3 & 248 & 67 & 20 & 3 \\
\hline $\begin{array}{l}\text { Vila France de Xira, } \\
\text { Portugal }\end{array}$ & 131 & 87 & 3 & 223 & 78 & 20 & 4 \\
\hline Marki, Poland & 62 & 88 & 5 & 248 & 90 & 21 & 3 \\
\hline All & 765 & 85 & 4 & 206 & 76 & 22 & 3 \\
\hline
\end{tabular}

*White bread as the reference food.

tSignificant difference in Gl and GL between towns/centres (Kruskal-Wallis or $\chi^{2}$ test): $P<0 \cdot 0001$
Cross-sectional and prospective analyses are presented in three adjustment models in Table 3. In the unadjusted analysis, mean baseline PPT scores decreased significantly across ascending dietary GI quintiles. With adjustment for age, BMI, physical activity, self-perceived health, chronic diseases and town/centre, the association became nonsignificant (Table 3). The magnitude of the association was higher in the unadjusted analysis than in the fully adjusted model (Fig. 1(a)). In the unadjusted analysis, the difference in dietary GI between the first quintile and the fifth quintile corresponded to a difference of 0.68 in PPT score.

In the unadjusted analysis, mean baseline PPT scores decreased significantly across ascending dietary GL quintiles (Table 3). This association remained significant after adjustment for age, BMI, physical activity, selfperceived health and chronic diseases, but became nonsignificant with additional adjustment for town/centre. The magnitude of the association was higher in the unadjusted analysis than in the fully adjusted model (Fig. 1(b)). In the unadjusted analysis, a difference in dietary GL between the first quintile and the fifth quintile corresponded to a difference of 0.64 in PPT score.

Three hundred and fifty-seven subjects of the baseline study sample had also completed the PPT in 1999. During the 6 years of follow-up, mean PPT score decreased significantly by 2.7 points from 22.6 to $19 \cdot 9$. Dietary GI and dietary GL were not significantly associated with PPT score 6 years later in the unadjusted analysis or after adjustment as indicated above (Table 3).

\section{Discussion}

Our results suggest that dietary GI/GL might play a significant role in physical performance among 75-80-yearold Europeans. We found a difference of 0.68 in PPT score between subjects in the first quintile and the fifth quintile of dietary GI, corresponding to an 18-month decrease in the PPT scores observed among the SENECA cohort. Equivalently, we found a difference of 0.64 in PPT

Table 3 Regression estimates of changes in Physical Performance Test (PPT) scores in 1993 ( $n$ 765) and 1999 ( $n$ 357) with changes of one quintile of dietary glycaemic index (GI)/glycaemic load (GL) in 1993. Data from the Survey in Europe on Nutrition and the Elderly, a Concerted Action

\begin{tabular}{|c|c|c|c|c|c|c|c|c|c|c|c|c|}
\hline \multirow{3}{*}{$\begin{array}{l}\text { Outcome } \\
\text { Predictor }\end{array}$} & \multicolumn{6}{|c|}{ PPT 1993, cross-sectional analyses } & \multicolumn{6}{|c|}{ PPT 1999, prospective analyses } \\
\hline & \multicolumn{3}{|c|}{ Gl quintiles } & \multicolumn{3}{|c|}{ GL quintiles } & \multicolumn{3}{|c|}{ GI quintiles } & \multicolumn{3}{|c|}{ GL quintiles } \\
\hline & $\beta$ & SEE & $P$ & $\beta$ & SEE & $P$ & $\beta$ & SEE & $P$ & $\beta$ & SEE & $P$ \\
\hline Model $1^{*}$ & $-0 \cdot 17$ & 0.08 & $0.03 \S$ & $-0 \cdot 16$ & 0.08 & $<0.05 \S$ & $-0 \cdot 11$ & $0 \cdot 12$ & 0.33 & 0.02 & $0 \cdot 12$ & 0.88 \\
\hline Model 2† & $-0 \cdot 11$ & 0.08 & $0 \cdot 15$ & $-0 \cdot 21$ & 0.07 & $<0.01 \S$ & $-0 \cdot 11$ & $0 \cdot 11$ & 0.34 & $<-0.01$ & $0 \cdot 11$ & 0.97 \\
\hline Model $3 \ddagger$ & -0.13 & 0.08 & 0.08 & $<-0.01$ & 0.08 & 0.92 & -0.05 & $0 \cdot 12$ & 0.69 & 0.05 & $0 \cdot 13$ & 0.69 \\
\hline
\end{tabular}

$\beta$, regression estimate; SEE, standard error of the $\beta$ estimate.

*Unadjusted model in 1993: adjusted for PPT score in 1993, where outcome is PPT score in 1999.

†Adjusted for same as Model 1 plus age, BMI, self-reported physical activity, self-perceived health and number of chronic diseases.

$\ddagger$ Adjusted for same as Model 2 plus town/centre.

$\S$ Significant association between dietary GI/GL and PPT score $(t$ test): $P<0.05$. 
(a)

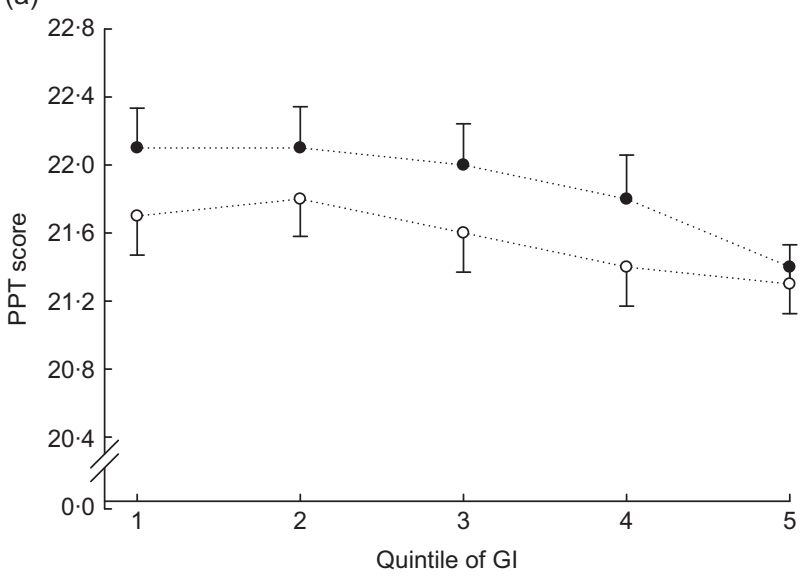

(b)

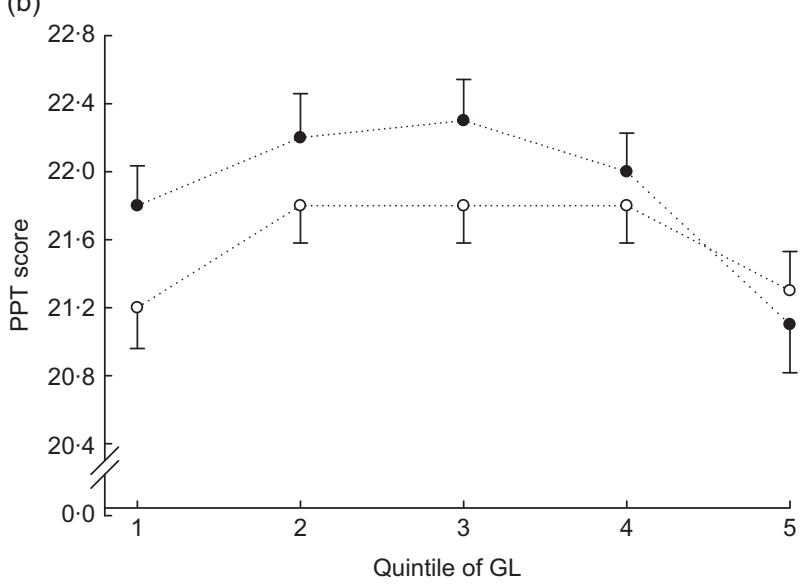

Fig. 1 Mean scores of the Physical Performance Test (PPT), with standard error of the mean represented by vertical bars, plotted as a function of dietary glycaemic index (GI) quintiles (a) and dietary glycaemic load (GL) quintiles (b) in unadjusted $(\cdots \bullet \cdots)$ and adjusted $(\cdots \circ \cdots)$ associations: Survey in Europe on Nutrition and the Elderly, a Concerted Action in 1993 ( $n$ 765). Adjusted associations include age, BMI, selfreported physical activity, self-perceived health, number of chronic diseases and town/centre. The linear trend across GI quintiles was $P=0.05$ unadjusted and $P=0.08$ adjusted and across GL quintiles was $P=0.05$ unadjusted and $P=0.92$ adjusted

score between subjects in the first quintile and the fifth quintile of dietary GL, corresponding to a 17-month change in the PPT scores observed among the SENECA cohort. This means that those consuming a diet with a high dietary GI/GL may have a 17-18-month accelerated age-related decrease in physical performance compared with those consuming a diet with low dietary GI/GL. No attempt was made to examine whether a high physical performance was caused by postprandial decreases in blood glucose elicited from a lower dietary GI/GL or high diet quality in itself ${ }^{(18)}$.

A borderline-significant association between dietary GI and physical performance at baseline remained after adjustment for several confounders. In addition, it seems that town/centre may have a particularly significant effect on the association between dietary GL and physical performance, as the magnitude of the association decreased substantially after we accounted for the possible clustering effect of geographical location. This could be caused by the large variation in habitual food intake across countries $^{(19)}$. From a previous study of SENECA subjects, we know that total energy intake was overestimated in the Polish centre and underestimated among men in the French centre ${ }^{(14)}$. This may partly explain the strong effect of town/centre on the association between dietary GL and physical performance. Another SENECA study has found that the total energy intake of the elderly people in some towns/centres decreased more than $1 \mathrm{MJ} / \mathrm{d}$ between $1988 / 89$ and $1993^{(20)}$. Such changes in habitual diet prior to baseline in our study may have weakened the causality of the cross-sectional association between dietary GI/GL and physical performance. Smoking, socio-economic status and dietary factors, including macronutrient intake, dietary fibre and alcohol intake, were not significant confounders in the present study.

We did not find a significant association between dietary GI/GL and physical performance 6 years later. It is likely that changes in health and social circumstances could have caused changes in the habitual diets between baseline and follow-up, which, in turn, may have attenuated the studied associations. However, the diet was not assessed at the follow-up study in 1999. Another explanation for the non-significant prospective results could be that subjects were more homogeneous than previously, and that the statistical power was weakened due to a reduced sample size in 1999 compared with 1993.

One major strength of the present study was the application of an objective test of physical performance, validated for use among healthy older subjects ${ }^{(21)}$. Measuring simple body functions makes it less likely that subjects have compensated for reduced strength by changing movements, which may be the case when measuring daily activities ${ }^{(21)}$. On the other hand, our study may be limited by the use of the diet assessment method, which was not constructed for studying dietary GI. However, the mean dietary GI was of the same magnitude among the SENECA cohort and elderly Dutch men from the Zutphen Elderly Study. In both studies the diets were assessed using a cross-check dietary history $\operatorname{method}^{(22)}$. Another caveat is that the international GI tables are based on studies of healthy young subjects and food items primarily from America and Australia. Therefore, international differences in food ingredients of habitual food items, e.g. wheat bread, may have resulted in misclassification of GI/GL. Despite a decreased glucose metabolism among elderly subjects, the GI ranking of food items may still be comparable to those of younger subjects $^{(3)}$. A low dietary GI would still decrease the postprandial glycaemic response among elderly subjects ${ }^{(23)}$. Finally, dietary intake, physical activity, self-perceived health and chronic diseases were all self-reported measures, 
and hence memory loss or subjective judgements may have influenced results.

In conclusion, a higher dietary GI/GL was associated with a lower concurrent physical performance among Europeans at 75-80 years of age. These associations did not remain significant after adjustment for age, BMI, physical activity, self-perceived health, chronic diseases and town/centre. Neither dietary GI, nor dietary GL, was associated with physical performance 6 years later.

\section{Acknowledgements}

The study was supported by the FREJA Programme and the Danish Research Agency. All co-authors have approved the submission of the manuscript and there are no conflicts of interest. Access to the SENECA database was facilitated by B.L.H. In cooperation with B.L.H., K.S.B. and I.T., I.K. planned the study purpose and interpreted the study results. K.S.B. was involved in the collection of the Danish SENECA data. I.K. performed the statistical data analyses with assistance of statistician Peder Frederiksen. We thank the SENECA investigators for skilful examination of participants.

\section{References}

1. Gill TM, Williams CS \& Tinetti ME (1995) Assessing risk for the onset of functional dependence among older adults: the role of physical performance. J Am Geriatr Soc 43, 603-609.

2. Knoops KT, Groot de LC, Fidanza F, Alberti-Fidanza A, Kromhout D \& van Staveren WA (2006) Comparison of three different dietary scores in relation to 10-year mortality in elderly European subjects: the HALE project. Eur J Clin Nutr 60, 746-755.

3. Teuscher AU, Reinli K \& Teuscher A (2001) Glycaemia and insulinaemia in elderly European subjects ( $70-75$ years). Diabet Med 18, 150-153.

4. Tavani A, Bosetti C, Negri E, Augustin LS, Jenkins DJ \& La Vecchia C (2003) Carbohydrates, dietary glycaemic load and glycaemic index, and risk of acute myocardial infarction. Heart 89, 722-726.

5. Jenkins DJ, Wolever TM, Taylor RH, Barker H, Fielden H, Baldwin JM, Bowling AC, Newman HC, Jenkins AL \& Goff DV (1981) Glycemic index of foods: a physiological basis for carbohydrate exchange. Am J Clin Nutr 34, 362-366.

6. Kirwan JP, Cyr-Campbell D, Campbell WW, Scheiber J \& Evans WJ (2001) Effects of moderate and high glycemic index meals on metabolism and exercise performance. Metabolism 50, 849-855.

7. Brand-Miller JC, Thomas M, Swan V, Ahmad ZI, Petocz P \& Colagiuri S (2003) Physiological validation of the concept of glycemic load in lean young adults. $J$ Nutr $\mathbf{1 3 3}$, $2728-2732$.
8. De Groot CPGM \& van Staveren WA (1988) Nutrition and the Elderly: Manual of Operations. Euronut Report no. 11. Wageningen, The Netherlands: WHO Special Programme for Research on Aging \& International Union of Nutritional Sciences.

9. van't Hof MA, Hautvast JG, Schroll M \& Vlachonikolis IG (1991) Design, methods and participation. Euronut SENECA investigators. Eur J Clin Nutr 45, Suppl. 3, 5-22.

10. Haveman-Nies A, de Groot LP, Burema J, Cruz JA, Osler M \& van Staveren WA (2002) Dietary quality and lifestyle factors in relation to 10-year mortality in older Europeans: the SENECA study. Am J Epidemiol 156, 962-968.

11. Reuben DB \& Siu AL (1990) An objective measure of physical function of elderly outpatients. The Physical Performance Test. J Am Geriatr Soc 38, 1105-1112.

12. Schroll M, Bjornsbo KS, Ferrt N \& Livingstone MB (1996) Health and physical performance of elderly Europeans. SENECA Investigators. Eur J Clin Nutr 50, Suppl. 2, S105-S111.

13. Nes M, van Staveren WA, Zajkas G, Inelmen EM \& Moreiras-Varela O (1991) Validity of the dietary history method in elderly subjects. Euronut SENECA investigators. Eur J Clin Nutr 45, Suppl. 3, 97-104.

14. van Staveren WA, Burema J, Livingstone MB, van den Broek T \& Kaaks R (1996) Evaluation of the dietary history method used in the SENECA Study. Eur J Clin Nutr 50, Suppl. 2, S47-S55.

15. Kohlmeier L (1992) The Eurocode 2 food coding system. Eur J Clin Nutr 46, Suppl. 5, S25-S34.

16. Foster-Powell K, Holt SH \& Brand-Miller JC (2002) International table of glycemic index and glycemic load values: 2002. Am J Clin Nutr 76, 5-56.

17. Food and Agriculture Organization of the United Nations (1998) Carbohydrates in Human Nutrition. FAO/WHO Expert Consultation. FAO Food and Nutrition Paper no. 66. Rome: FAO.

18. Davis MS, Miller CK \& Mitchell DC (2004) More favorable dietary patterns are associated with lower glycemic load in older adults. J Am Diet Assoc 104, 1828-1835.

19. Schroll K, Carbajal A, Decarli B, Martins I, Grunenberger F, Blauw YH \& de Groot CP (1996) Food patterns of elderly Europeans. SENECA Investigators. Eur J Clin Nutr 50, Suppl. 2, S86-S100.

20. Moreiras O, van Staveren WA, Amorim Cruz JA, Carbajal A, de Henauw S, Grunenberger F \& Roszkowski W (1996) Longitudinal changes in the intake of energy and macronutrients of elderly Europeans. SENECA Investigators. Eur J Clin Nutr 50, Suppl. 2, S67-S76.

21. Brach JS, van Swearingen JM, Newman AB \& Kriska AM (2002) Identifying early decline of physical function in community-dwelling older women: performance-based and self-report measures. Phys Ther 82, 320-328.

22. van Dam RM, Visscher AW, Feskens EJ, Verhoef $\mathrm{P}$ \& Kromhout D (2000) Dietary glycemic index in relation to metabolic risk factors and incidence of coronary heart disease: the Zutphen Elderly Study. Eur J Clin Nutr 54, 726-731.

23. Kaplan RJ \& Greenwood CE (2002) Influence of dietary carbohydrates and glycaemic response on subjective appetite and food intake in healthy elderly persons. Int $J$ Food Sci Nutr 53, 305-316. 